\title{
Estudo de propagação de ondas para auxiliar a elaboração do plano de ação emergencial externo - PAE
}

\section{Study of wave propagation to assist in the preparation of the external emergency action plan-PAE}

\author{
Euclydes Cestari Jr ${ }^{1}$; Milton Dall'Aglio Sobrinho ${ }^{2}$ e Jefferson Nascimento de Oliveira ${ }^{3}$ \\ ${ }^{1,2,3}$ Universidade Estadual Paulista - UNESP - FEIS, Ilha Solteira, SP \\ euclydes.cestari@cesp.com.br; milton@dec.feis.unesp.br; jeffno@dec.feis.unesp.br
}

Recebido: 04/04/14 - Revisado: 20/12/14 - Aceito: 20/04/15

\begin{abstract}
RESUMO
Este estudo atende às diretrizes da Lei 12.334/2010, da Politica Nacional de Segurança de Barragens, e busca avaliar ondas de cheia geradas por vazões indużidas e por ruptura hipotética de barragempara elaboração de um Plano de Ação Emergencial. O trabalho foi desenvolvido na UHE Três Irmãos, no Rio Tietê, da CESP - Companbia Energética de São Paulo. As ondas foram propagadas por $30 \mathrm{~km}$ com o modelo HEC-R AS, calibrado a partir da reproducão de niveis observados com vazões históricas. Foram determinados os tempos de chegada da onda, período de submersão, cotas e velocidades em diferentes pontos de interesse ao longo do rio, para diferentes cenários. Foram elaborados mapas de inundação, base para definição de um plano de evacuação da população impactada. Os hidrogramas de ruptura gerados resultaram em vazões máximas entre 20.915 e $40.507 \mathrm{~m}^{3} / \mathrm{s}$, com tempos de abertura de brecha entre 1,0 e 14,0 h. O tempo de abertura da brecha pouco influiu na extensão e tempo de submersão das áreas atingidas, apenas mudando o tempo de chegada do pico. Os niveis calculados com regime permanente e variável foram semelhantes. Verificou-se baixa atenuação da vazão máxima ao longo do trecho devido ao grande volume de esvaziamento do reservatório. Não se identificou risco de ruptura em cascata, já que a barragem de Jupiá, a jusante, pode controlar vazões até $50.000 \mathrm{~m}^{3} / \mathrm{s}$.
\end{abstract}

Palavras Chave: Propagação de ondas. Ruptura de barragens

\begin{abstract}
This study meets the guidelines of the Act 12.334/2010 of the National Dam Safety and aims to assess the flood waves caused by full flow operation and flow induced by hypothetical dam rupture, for the preparation of an Emergency Action Plan. The study was developed in HPP Três Irmãos, in Rio Tietê, CESP - Companbia Energética de São Paulo. The flood waves were propagated along a $30 \mathrm{~km}$ reach, using the HEC-RAS model, calibrated from the reproduction of historical water levels. The methodology seeks to determine the peak arrival times, period of submersion, water levels and velocities at different points of interest along the river for different scenarios. Flood maps were made to serve as the basis for defining a plan for evacuation of the affected population. The outflow hydrographs generated resulted in peak. flows between 20.915 and $40.507 \mathrm{~m}^{3} / \mathrm{s}$, with breach opening times between 1 and 14 h. The results showed little influence of the breach opening time in the extent and time of submersion of the affected areas, with only appreciable difference in arrival time of the peak. The simulations in steady and unsteady flow regimes showed no large variations of the maximum water depth. It was observed small attenuation of the max flow rate along the river reach due to the large reservoir storage and the long depletion time. The risk of cascade rupture was not identified, because the downs tream Jupiá dam can control flow rates up to $50.000 \mathrm{~m}^{3} / \mathrm{s}$.
\end{abstract}

Keywords: Wave propagation. Dam Break 


\section{INTRODUÇÃO}

Segundo a Agência Nacional de Águas (ANA, 2012), o Brasil dispõe de 13.776 barragens cadastradas pelas entidades fiscalizadoras federais e estaduais. Esse cadastro revela que 11.946 barragens são de usos múltiplos (utilizadas para abastecimento humano, irrigação, abastecimento industrial, lazer e dessedentação animal), 1.261 são para geração de energia hidrelétrica, 264 de rejeitos de mineração e 265 de resíduos industriais.

A legislação brasileira sobre segurança de barragens é relativamente nova, e os órgãos de fiscalização ainda estão adequando as suas estruturas à nova legislação.

A Lei 12.334/2010 estabeleceu a Política Nacional de Segurança de Barragens e criou o Sistema Nacional de Informações sobre Segurança de Barragens, determinando que as barragens destinadas à acumulação de águas para quaisquer usos, classificadas como de Dano Potencial Alto, devem apresentar um Plano de Ação Emergencial - PAE (BRASIL, 2010). Este plano é um documento formal que identifica condições de emergência em potencial da barragem e estabelece ações a serem seguidas, com a finalidade de mitigar o efeito provocado pelas ondas de cheia, quer seja por defluências induzidas ou pela onda provocada pela ruptura de uma barragem.

De acordo com o Boletim 111 do Comitê Internacional de Grandes Barragens, INTERNATIONAL COMISSION OF LARGE DAMS (1998), uma metodologia de análise de ruptura de barragem pode ser descrita em quatro passos: elaboração do hidrograma de ruptura, propagação da onda de cheia, geração de mapas de inundação e elaboração do plano de contingência.

As informações públicas disponíveis no país não oferecem precisão requerida para o estudo (tais como as cartas geodésicas). Este trabalho consiste numa proposta de metodologia que sirva de base ao planejamento de medidas de proteção para regiões situadas a jusante de barragens e, por outro lado, como definição de regras que permitam elaborar os Planos de Emergência Externos a partir de dados e informações públicas, ferramentas de baixo custo e software livre, em virtude da Medida Provisória - MP n579, de setembro de 2012, atualmente Lei Federal no 12.783 de 11 de janeiro de 2013. (BRASIL, 2013), que dispõe sobre a redução de encargos setoriais.

Os estudos foram desenvolvidos com o software livre HEC-RAS, que é um modelo unidimensional de fluxo contínuo destinado para computadores e cálculos de perfil de água de superfície. Os resultados do modelo são tipicamente aplicados na elaboração de modelos de inundação (HYDROLOGIC ENGINEERING CENTER, 1997). Foram realizadas simulações em regime permanente e em regime variável.

\section{MATERIAL E MÉTODO}

\section{Descrição da Barragem}

A Barragem de Três Irmãos está localizada na bacia do rio Tietê, $32 \mathrm{~km}$ acima da confluência com o rio Paraná, no município de Pereira Barreto (SP). A montante da usina encontra-se a usina Nova Avanhandava, no mesmo rio, e a jusante, no rio Paraná, a usina de Jupiá. A Tabela 1 apresenta os dados de interesse para a operação hidráulica da Usina Hidrelétrica Três Irmãos.

Tabela 1 - Dados hidráulicos da UHE Três Irmãos

\begin{tabular}{l|c}
\hline Área da bacia hidrográfica & $69900 \mathrm{~km}^{2}$ \\
\hline Volume total & $13800 \times 10^{6} \mathrm{~m}^{3}$ \\
\hline Comprimento no coroamento & $3640,00 \mathrm{~m}$ \\
\hline Altura máxima & $62,00 \mathrm{~m}$ \\
\hline N.A. montante/jusante & $328,00 / 279,00 \mathrm{~m}$ \\
\hline $\begin{array}{l}\text { Vazão média a longo tempo } \\
\text { (MLT período 1931/1998 }\end{array}$ & $757 \mathrm{~m}^{3} / \mathrm{s}$ \\
\hline $\begin{array}{l}\text { Vazão máxima média diária } \\
\text { observada (05/06/83) }\end{array}$ & $6575 \mathrm{~m}^{3} / \mathrm{s}$ \\
\hline $\begin{array}{l}\text { Vazão máxima dos } \\
\text { descarregadores no N.A. } 328,00 \mathrm{~m}\end{array}$ & $9500 \mathrm{~m}^{3} / \mathrm{s}$ \\
\hline $\begin{array}{l}\text { Vazão turbinada nominal total } \\
\text { (5 máquinas) }\end{array}$ & $2040 \mathrm{~m}^{3} / \mathrm{s}$ \\
\hline
\end{tabular}

Fonte: CESP

\section{Análise de Risco da Barragem de Três Irmãos}

As barragens da CESP foram submetidas à análise de risco (CESP, 2006), segundo a metodologia proposta por Foster e Fell (1999), que considera três fatores para ruptura de barragem de terra:

- suscetibilidade de erosão interna ou piping;

- probabilidade de faturamento hidráulico devido às baixas tensões confinantes; e

- probabilidade de infiltração concentrada em zonas de elevada permeabilidade.

Esses fatores foram avaliados no solo empregado na barragem da UHE Três Irmãos, verificando-se a densidade de compactação, teor de umidade de compactação e tipo de solo, chegando-se às seguintes conclusões:

- o solo da barragem de terra foi bem compactado;

- a densidade de compactação foi maior do que a densidade seca máxima;

- a umidade foi acima da ótima para argilas finas de alta plasticidade e siltes fino sem coesão;

- os recalques medidos na barragem Três Irmãos com instrumentos de auscultação civil foram de baixas magnitudes;

- comparação dos módulos de deformabilidade adotados em projeto e observados no campo indica aterro e fundação pouco deformáveis;

- a barragem apresenta seção transversal homogênea, sem possibilidade de deformabilidade diferencial entre 
materiais;

- o desvio do rio durante a construção da barragem foi realizado pelas estruturas de concreto, não prejudicando em nada as barragens de terra da margem esquerda e direita;

- material de fundação: rocha sã devidamente tratada; - compactação cuidadosa junto aos paramentos e muros de ligação.

Associado a esses fatores foram criadas as seguintes árvores de evento, onde P é probabilidade derupturapelos eventos: - erosão interna através de interface concreto/solo na eclusa, com probabilidade de ruptura $\mathrm{P}=4,3 \times 10^{-7}$;

- erosão interna através de interface concreto/solo nos abraços, com probabilidade de ruptura $\mathrm{P}=6,7 \times 10^{-7}$; - erosão por galgamento - cheia excepcional, com probabilidade de ruptura $\mathrm{P}=2,3 \times 10^{-5}$;

- escorregamento através de fundação, levando-se em consideração a perda de eficiência do sistema de drenagem, com probabilidade $\mathrm{P}=2,5 \times 10^{-7}$;

A probabilidade total de ruptura da barragem da UHE Três Irmãos segundo os estudos propostos por Foster e Fell foi de $\mathrm{P}=2,4 \times 10^{-5}$. Estudos semelhantes realizados nas barragens de Ilha Solteira e Jupiá resultaram $\mathrm{P}=4,2 \times 10^{-6}$ e P = 8,3 x 10 ${ }^{-5}$, respectivamente (CESP, 2006). Valores estes considerados para barragens de bom desempenho.

Após análise da probabilidade de ruptura das estruturas que compõem a barragem Três Irmãos (Barragem Margem Direita, Barragem Margem Esquerda, Barragem de Concreto e Eclusa), concluiu-se que o maior risco estava associado à erosão superficial causada por galgamento, ou volume excepcional defluído por acidente com barragem a montante.

\section{Classificação da Barragem}

Segundo o Art. $7^{\circ}$ da Lei 12.334/2010, as barragens serão classificadas pelos agentes fiscalizadores por categoria de risco, por dano potencial associado e pelo seu volume, com base em critérios gerais estabelecidos pelo Conselho Nacional de Recursos Hídricos (CNRH).

A classificação por categoria de risco em alto, médio ou baixo será feita em função das características técnicas, do estado de conservação do empreendimento e do atendimento ao Plano de Segurança da Barragem. A classificação por categoria de dano potencial associado à barragem em alto, médio ou baixo será feita em função do potencial de perdas de vidas humanas e dos impactos econômicos, sociais e ambientais decorrentes da ruptura da barragem.

Seguindo as matrizes de classificação de barragens estabelecidas nas resoluções da ANA e do CNRH, a barragem de Três Irmãos foi classificada como sendo de Risco Baixo e Dano Potencial Alto, havendo, portanto, a necessidade de elaboração de Plano de Ação Emergencial, que deverá estar disponível na Empresa responsável pela barragem, nas prefeituras envolvidas e na Defesa Civil.

O tempo eficaz de aviso permite que as pessoas preparem a mobilização e a evacuação das zonas mais sensíveis, sendo este o fator primordial para a mitigação da consequência das cheias.

Para definir o grau de perigo em função da combinação da profundidade $(\mathrm{H})$ e da velocidade $(\mathrm{V})$, adotou-se o Risco Hidrodinâmico (R.H. $\left.=\mathrm{V}^{*} \mathrm{H}\right)$. A Tabela 2 apresenta os critérios adotados por Viseu (1999), em Portugal, para graduação do risco em função da altura do escoamento e da velocidade.

Tabela 2 - Graduação do perigo para seres humanos

\begin{tabular}{llll}
\hline Nível & Classe & $\begin{array}{l}\text { Inundação } \\
\text { Estática }(\mathrm{H})\end{array}$ & $\begin{array}{l}\text { Inundação } \\
\text { Dinâmica } \\
\left(\mathrm{H}^{*} \mathrm{~V}\right)\end{array}$ \\
\hline Reduzido & Verde & $\mathrm{H}<1,0 \mathrm{~m}$ & $\begin{array}{l}\mathrm{H}^{*} \mathrm{~V}<0,5 \\
\mathrm{~m}^{2} / \mathrm{s}\end{array}$ \\
\hline Médio & Amarelo & $1,0 \mathrm{~m}<\mathrm{H}<$ & $\begin{array}{l}0,5 \mathrm{~m}^{2} / \mathrm{s}< \\
\mathrm{H}^{*} \mathrm{~V}<0,75\end{array}$ \\
& & $3,0 \mathrm{~m}$ & $\mathrm{~m}^{2} / \mathrm{s}$ \\
\hline Importante & Laranja & $3,0 \mathrm{~m}<\mathrm{H}<$ & $0,75 \mathrm{~m}^{2} / \mathrm{s}<$ \\
& & $6,0 \mathrm{~m}$ & $\begin{array}{l}\mathrm{H}^{*} \mathrm{~V}<1,0 \\
\mathrm{~m}^{2} / \mathrm{s}\end{array}$ \\
\hline $\begin{array}{l}\text { Muito } \\
\text { Importante }\end{array}$ & Vermelho & $\mathrm{H}>6,0 \mathrm{~m}$ & $\begin{array}{l}\mathrm{H}^{*} \mathrm{~V}>1,0 \\
\mathrm{~m}^{2} / \mathrm{s}\end{array}$ \\
\hline
\end{tabular}

Fonte: Viseu 1999

\section{Levantamento batimétrico e topográfico}

A partir de mapa de satélite da base Google, foram definidas as seções batimétricas sobre as quais foram justapostas as seções transversais de medição com as suas respectivas coordenadas georreferenciadas para ambas as margens. A Figura 1 mostra o trecho do rio com a representação esquemática dos pontos de realização da batimetria e de medição de vazão.

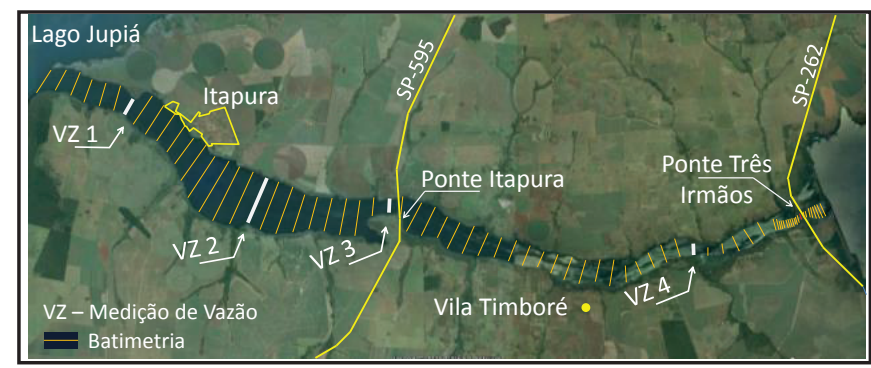

Figura 1 - Rio Tietê definido com as seções batimétricas Fonte: adaptado de Cestari (2013)

O levantamento topográfico de campo foi realizado através de nivelamento geométrico de 8 seções nas margens esquerda e direita do rio Tietê. As cotas foram plotadas no mapa georreferenciado. Com a utilização do software autoCAD foi possível sobrepor as curvas de nível do IGC - Instituto de Geografia e Cartografia com o levantamento de campo, permitindo a calibração, interpolação e o traçado de novas curvas de nível intermediárias de 1,00 em 1,00 metro. O desenho final foi utilizado como base de dados para a elaboração do modelo digital de terreno - MDT.

De posse dos levantamentos batimétricos e das curvas 
de nível, foi possível obter os perfis seco e molhado de cada seção. Os resultados de cálculo dos perímetros e das áreas para as seções secas e molhadas foram transportados para uma planilha, que serviu como base de dados para aplicação no modelo HEC-RAS de propagação de ondas.

\section{Vazão de pico e hidrograma de ruptura defluente}

Para simular o evento de ruptura foram utilizadas expressões matemáticas relacionadas com a máxima vazão de descarga e características da barragem, segundo vários autores. As características principais a serem determinadas referem-se à forma da brecha e ao seu tempo de formação (PALMIER, et al.,2005). A Tabela 3 apresenta as fórmulas consideradas para determinação das vazões de pico.

As equações apresentadas na Tabela 3 podem ser resultantes de modelos empíricos ou paramétricos. Os modelos baseados em equações empíricas utilizam expressões que relacionam o volume máximo efluente da brecha com as características da barragem (geralmente altura e volume armazenado). Estas expressões foram desenvolvidas tendo por base caso de estudos derivados de rupturas históricas. Nos modelos paramétricos são definidas as geometrias da brecha (largura, forma final) e o tempo de ruptura, após tratamento estatístico de informações obtidas de rupturas históricas e modelos físicos. Esses modelos simulam a formação da brecha em função do tempo e calculam o hidrograma resultante segundo princípios da hidráulica. Para representar o tempo de esvaziamento do reservatório neste trabalho, foi utilizado um hidrograma triangular.

Tabela 3 - Diferentes fórmulas matemáticas para determinar as vazões de pico

\begin{tabular}{ll}
\hline Autor & Vazão Máxima $(\mathrm{m} 3 / \mathrm{s})$ \\
\hline $\begin{array}{l}\text { Lou (1961) apud } \\
\text { Mascarenhas (1990) }\end{array}$ & $Q_{\max }=7,683 H_{d}^{1,909}(1)$ \\
\hline $\begin{array}{l}\text { Saint-Venant (-) apud U.S } \\
\text { Army Corps of Enginners }\end{array}$ & $Q_{\max }=\frac{8}{27} B \sqrt{g} Y_{\text {médio }}^{3 / 2}(2)$ \\
\hline Hagen (1982) & $Q_{\max }=1,205\left(H_{d} V\right)^{0,48}$ \\
\hline Bureau ofReclamation & $Q_{\max }=19 H_{d}^{1,85} \quad(4)$ \\
\hline $\begin{array}{l}\text { Vertedor de Soleira } \\
\text { Espessa, Singh (1987) }\end{array}$ & $Q_{\max }=1,7 B_{b} H_{b}^{3 / 2}$ \\
\hline $\begin{array}{l}\text { WetmoreFread (1981) } \\
\text { apud French (1985) }\end{array}$ & $Q_{\max }=$ \\
& $1,7 B_{b}\left\{\frac{1,94 \frac{A_{t}}{B_{b}}}{T_{p}+\left[\frac{1,94 A_{t}}{\left(B_{b} \cdot \sqrt{H_{d}}\right)}\right]}\right\}$ \\
\hline
\end{tabular}

Fonte Balbi (2008)

Segundo Viseu (1999), alguns autores também propuseram fórmulas para determinar o tempo de ruptura de uma barragem, levando em consideração as dimensões das brechas, características da barragem e o seu volume. Asbrechas em barragens de aterro apresentam geometria trapezoidal com uma inclinação dos lados da ordem de $2 \mathrm{~V}: 1 \mathrm{H}$ nos casos em que a erosão do aterro atinge a fundação e continua a evoluir. No caso em que a erosão não atinge a fundação, a geometria da brecha apresenta uma forma triangular com inclinação igual dos lados.

\section{Propagação da onda de ruptura}

Dentre as ferramentas existentes para a modelagem de propagação de cheia, escolheu-se o modelo numérico HEC-RAS 4.1.0. O HEC-RAS vem sendo desenvolvido desde a década de 1960 pelo Centro Hidrológico de Engenharia - HEC do Exército dos EUA - CorpsofEngineers. O programa HEC-RAS pode ser baixado gratuitamente a partir da página doCentro de Engenharia Hidrológica em: www.wrchec.usace.army.mil. Um Manual do Usuário também está disponível nesse local.

As vazões foram propagadas em uma extensão de 30 $\mathrm{km}$ desde a usina até a confluência com o rio Paraná. Após a confluência, o modelo considerou o reservatório da UHE de Jupiá por meio de sua relação cota-volume e de uma seção com os dispositivos de descarga e suas respectivas relações cota-vazão. Duas seções foram acrescentadas a jusante da barragem para representar o rio Paraná, adotando-se como condição de contorno de jusante nesse trecho o escoamento com altura normal.

Foi adotado o mesmo nível d'água inicial no reservatório de Jupiá para todos os casos estudados. Isto se justifica porque a usina de Jupiá opera a fio d'água, sendo possível controlar vazões até cerca de $50.000 \mathrm{~m}^{3} / \mathrm{s}$ com manobras dos órgãos extravasores, mantendo o nível d’água no máximo operacional.

\section{RESULTADOS E COMENTÁRIOS}

\section{Caracterizações das seções}

As seções dos levantamentos batimétricos e topográficos foram sobrepostas a partir das coordenadas georreferenciadas (466.000 E-7.718.000 N), obtendo-se os perfis seco e molhado para cada seção. Foram utilizadas 84 seções para modelar o trecho de cerca de $30 \mathrm{~km}$ até o reservatório de Jupiá. A parte seca de 8 seções foideterminada com levantamento topográfico de campo; e as demais, com curvas de nível ajustadas. A Figura 2 apresenta a carta com as curvas de nível a cada metro.

Além do trecho de rio, o modelo incluiu ainda o reservatório da UHE de Jupiá, modelado como área de armazenamento a partir de sua curva de cota - volume.

\section{Calibração do modelo - coeficientes de rugosida- de e perdas localizadas}

O coeficiente de rugosidade no canal principal do rio foi ajustado a partir de vazões históricas e leituras realizadas em duas réguas. A primeira instalada no canal de fuga da UHE Três Irmãos, e a segunda na barragem de Jupiá a jusante, no Rio Paraná. O estudo consistiu na variação do coeficiente de rugosidade até se obter um valor experimental próximo ao real na seção mais próxima da UHE Três Irmãos.

Para o ajuste do modelo foram adotados ainda coeficientes de perdas localizadas nas seções das pontes, baseado nas faixas de variação indicadas no manual de referência do 


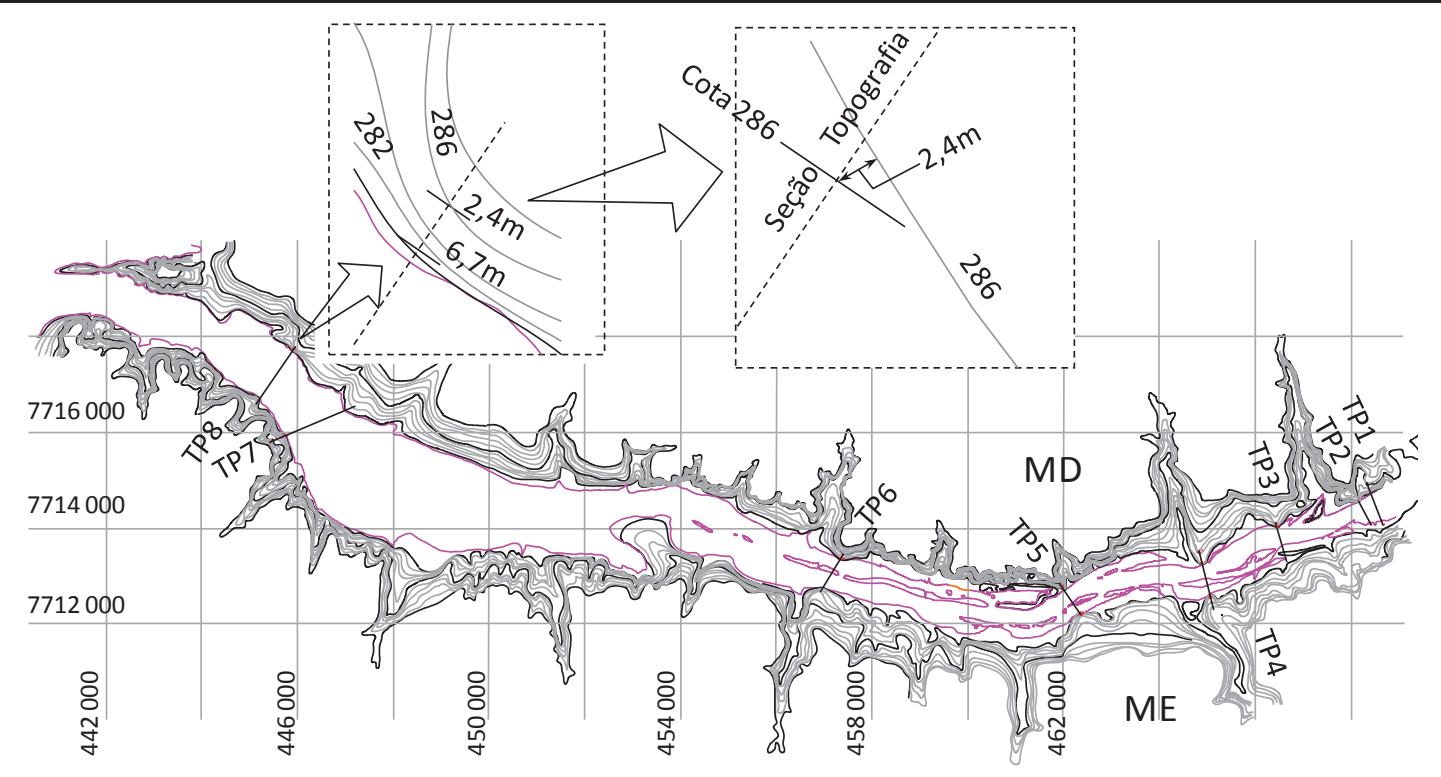

Figura 2 - Curvas de nível e seções topográficas levantadas, com detalhe ilustrando o ajuste das curvas às cotas levantadas em campo Fonte: adaptado de Cestari (2013)

HEC-RAS (HEC,2010) e levando em conta a proporção do estrangulamento da seção. Para a ponte de Itapura foi adotado um coeficiente de contração de 1,05, e para a ponte de Três Irmãos, 1,20. Para a seção 24,coeficiente de contração de 0,5 e expansão de 0,3 ; para a seção 23 , coeficiente de contração de 0,5 e expansão de 0,5 .

A Tabela 4 ilustra o erro obtido para o coeficiente adotado/calibrado de 0,028 , utilizado no canal principal.

Tabela 4 - Resultado da calibração do HEC-RAS

\begin{tabular}{ccccc}
\hline $\begin{array}{c}\text { Vazões } \\
\text { históricas } \\
\left(\mathrm{m}^{3} / \mathrm{s}\right)\end{array}$ & $\begin{array}{c}\text { NA - régua } \\
\text { UHE Jupiá } \\
(\mathrm{m})\end{array}$ & $\begin{array}{c}\text { NA - régua } \\
\text { UHE Três } \\
\text { Irmãos }(\mathrm{m})\end{array}$ & $\begin{array}{c}\text { Simulação } \\
\text { HEC-RAS } \\
(\mathrm{m})\end{array}$ & Erro $(\%)$ \\
\hline 2000,46 & 279,56 & 280,518 & 280,520 & 0,0006 \\
\hline 3099,75 & 279,13 & 281,658 & 281,150 & 0,1805 \\
\hline 3529,67 & 279,70 & 281,905 & 281,590 & 0,1116 \\
\hline 3962,58 & 279,81 & 282,088 & 281,870 & 0,0772 \\
\hline 4542,21 & 279,79 & 282,400 & 282,220 & 0,0637 \\
\hline
\end{tabular}

Para a propagação das vazões de cheia, o modelo utilizou a rugosidade ajustada para o canal principal, e as margens inundadas foram modeladas com coeficientes de rugosidade adotados com base em valores propostos na literatura (HOGGAN, 1996; CHOW, 1959). Os coeficientes adotados para as margens foram de 0,06 a 0,1 para matas e canavial, 0,04 a 0,06 para enrocamento e 0,03 a 0,035 para terra gradeada e pastos. A maior parte da extensão das margens, cerca de $78 \%$ na margem esquerda e 76\% na margem direita, foi classificada com $n=0,1$.

A Figura 3 apresenta os perfis da linha d'água obtidos através da simulação com base nos dados históricos de vazões observadas na UHE Três Irmãos e níveis d'água obtidos na régua da UHE Jupiá. Observa-se que os efeitos hidrodinâmicos do escoamento no canal predominam nos primeiros $20 \mathrm{~km}$. A partir daí praticamente não há variação do nível d'água devido à grande área inundada da represa da UHE Jupiá e às baixas velocidades resultantes.

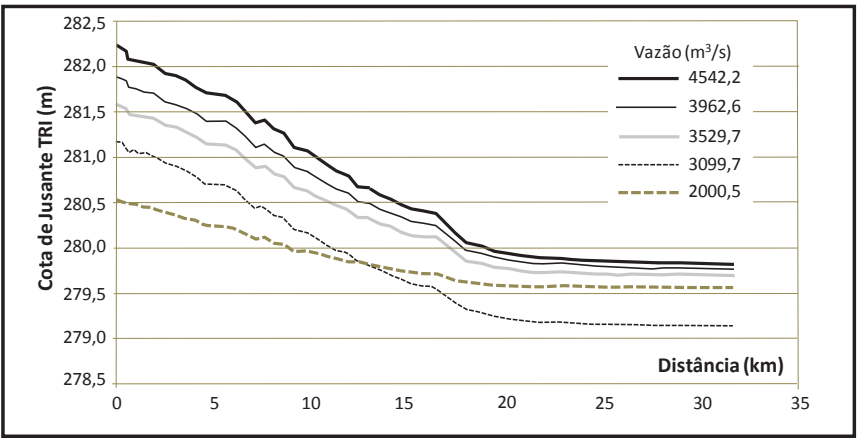

Figura 3 - Perfis da linha d'água com vazões históricas utilizadas na calibração

\section{Definição das cheias induzidas pela ruptura}

Diante dos estudos sobre o risco da barragem,definiuse por simular a ocorrência de ruptura da barragem de terra por galgamento e erosão superficial, utilizando-se as equações apresentadas na Tabela 3, com as considerações a seguir.

Dentre as fórmulas empíricas de previsão, a de Lou, 1981 (equação 1), resultou em vazão de $20.915 \mathrm{~m}^{3} / \mathrm{s}$, e a do Bureau of Reclamation (equação 4), em vazão de $40.507 \mathrm{~m}^{3} / \mathrm{s}$. As demais expressões resultaram em vazões intermediárias, exceto a equação 3 (Hagen, 1982), a única que considera o volume armazenado, que resultou em vazão de $454.850 \mathrm{~m}^{3} / \mathrm{s}$. Esse resultado foi desprezado porque o volume do reservatório é muito maior que os considerados no corpo de dados que deu origem à equação de Hagen.

Com relação à definição geométrica das brechas, a expressão proposta por Von Thun e Gillette resultou em uma largura de brecha de 130,00 m. As demais expressões resultaram 
em valores inferiores para as brechas. A brecha de 130,00 m aplicada à equação 5 resultou em vazão de $36.314 \mathrm{~m}^{3} / \mathrm{s}$.

\section{Definição dos Cenários para as Simulações}

Tendo em vista as vazões previstas pelas diversas equações da Tabela 3, decidiu-se adotar as vazões de pico de $20.915 \mathrm{~m}^{3} / \mathrm{s}$ e $40.507 \mathrm{~m}^{3} / \mathrm{s}$. A estas vazões foram acrescentadas a máxima vazão histórica $\left(4.600 \mathrm{~m}^{3} / \mathrm{s}\right)$ e a máxima vazão controlada $(11.000 \mathrm{~m} 3 / \mathrm{s})$, em simulação estática, resultando em 4 cenários apresentados na Tabela 5. Os cenários (3) e (4) consideram uma vazão inicial do rio de $2.000 \mathrm{~m} 3 / \mathrm{s}$.

Nos 2 cenários adotados para a ruptura por abertura da brecha, as equações para tempo de abertura resultaram em tempos variando entre $1 \mathrm{~h}$ e $14 \mathrm{~h}$. Dada a grande incerteza neste parâmetro, foram considerados hidrogramas de ruptura com $1 \mathrm{~h}$ e $14 \mathrm{~h}$ de tempo de pico para cada um dos cenários de ruptura, resultando em 4 simulações transientes. Após o pico considerou-se uma diminuição linear da vazão devido ao esvaziamento do reservatório. O tempo de base resultante foi de $366 \mathrm{~h}$ para o cenário 3, e de 189 h para o 4 . Os 4 cenários contendo 6 simulações são apresentados na Tabela 4. Os cenários (3) e (4) consideram uma vazão inicial do rio de $2.000 \mathrm{~m}^{3} / \mathrm{s}$.

Tabela 5 - Cenários considerados para a simulação

\begin{tabular}{lccc}
\hline Cenários & $\begin{array}{c}\text { Vazão } \\
\left(\mathrm{m}^{3} / \mathrm{s}\right)\end{array}$ & $\begin{array}{c}\text { Tempo de } \\
\text { Pico }(\mathrm{h})\end{array}$ & $\begin{array}{c}\text { Tempo de } \\
\text { Base }(\mathrm{h})\end{array}$ \\
\hline 1 - maior cheia & 4.600 & -- & -- \\
\hline 2 - operação extrema & 11.000 & -- & -- \\
\hline 3 - vazão de ruptura & 20.915 & 1 e 14 & 366 \\
\hline 4 - vazão de ruptura & 40.507 & 1 e 14 & 189 \\
\hline
\end{tabular}

\section{Resultados das Simulações}

Para teste de estabilidade da solução numérica do modelo, foi propagado um hidrograma triangular com vazão de pico de $80.000 \mathrm{~m}^{3} / \mathrm{s}$ e tempo de pico de 1 hora, com esvaziamento do reservatório em cerca de 90 horas. O programa rodou sem problemas de convergência ou de estabilidade da solução, com intervalos de tempo na simulação desde 1 minuto até 15 minutos.

A Figura 4 ilustra uma comparação entre os níveis da água obtidos nos cenários de simulação realizados em regime permanente e regime variável. No caso de regime variável, tem-se o perfil dos máximos níveis atingidos em cada seção.

Nota-se que existe pouca diferença entre as curvas das duas situações, embora a curva de níveis máximos da simulação dinâmica fique consistentemente abaixo do perfil estático, pelo menos no trecho inicial até cerca de 18,0 Km.

Esse resultado ocorreu devido ao grande volume de água armazenado no reservatório, que levou a hidrogramas de ruptura com grandes tempos de base e variações lentas de vazão no trecho de recessão após a vazão máxima. Com isso o hidrograma de ruptura causou, após o tempo de pico, um escoamento próximo ao da modelagem em regime permanente.

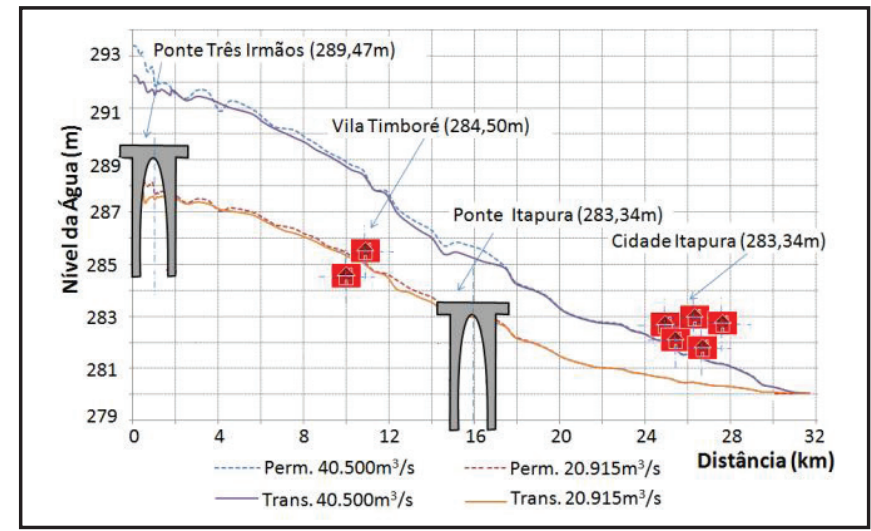

Figura 4 - Perfil da linha d'água para os cenários de simulação em regime permanente e regime variável com as cotas topográficas dos locais de interesse

Por exemplo, um perfil de vazões ocorridas ao longo do trecho no cenário 3, para o tempo de 6 horas após a ruptura, indica uma vazão de $20.700 \mathrm{~m}^{3} / \mathrm{s}$ na Ponte de Três Irmãos, reduzindose a $20.490 \mathrm{~m}^{3} / \mathrm{s}$ em Itapura. Isto significa que haveria pouco erro em estimar as áreas inundadas a partir dos resultados da simulação estática. Pode-se deduzir também que na recessão do hidrograma, os termos de inércia foram pequenos em relação aos demais termos da equação de Saint Venant.

Outra característica que contribui para explicar a baixa atenuação das vazões no trecho é a propagação da cheia sobre um trecho de rio já inundado pela barragem de jusante. As seções molhadas resultantes já incorporam, em regime permanente, as planícies de inundação do leito original do rio. Assim,

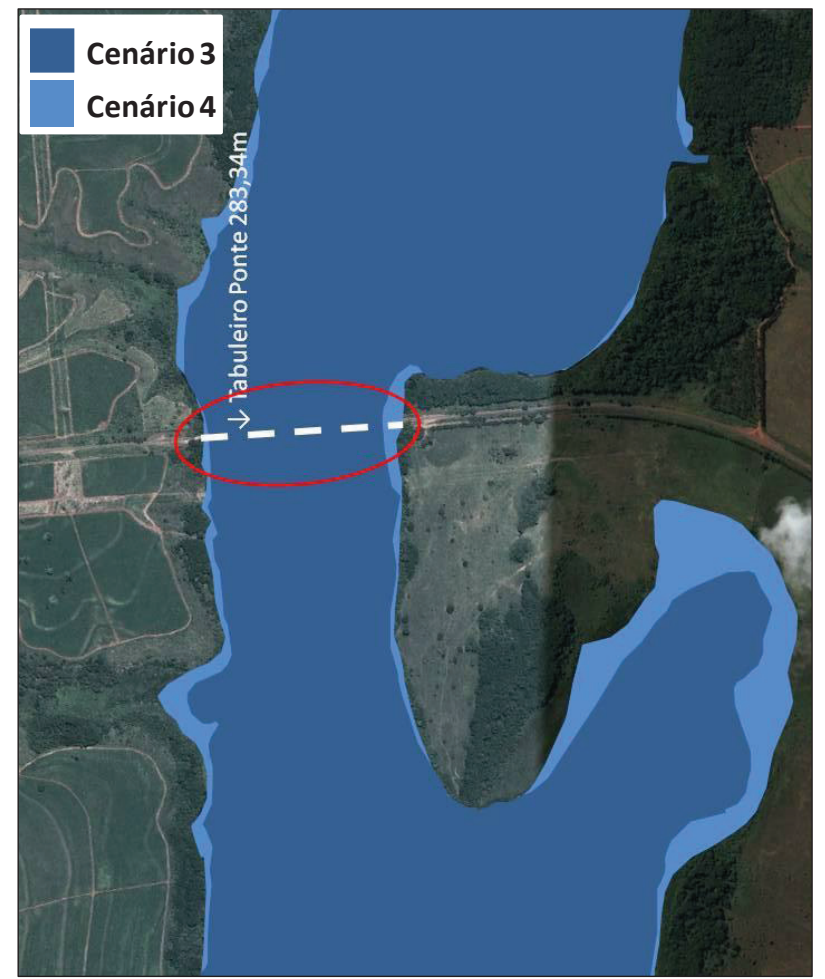

Figura 5-Mapa de inundação dos cenários 3 e 4 nas proximidades da Ponte Itapura. Fonte: Cestari (2013) 
as variações de largura do canal foram relativamente pequenas. Por exemplo, na Vila Timboré, a largura máxima da seção no cenário (3) atingiu apenas $110 \%$ da largura original, e no cenário (4), a largura máxima foi cerca de $180 \%$ superior à original. Para a mesma seção, a condutância hidráulica das áreas laterais em relação à condutância total cresceu de apenas 14\% no cenário (3) para cerca de 30\% no cenário (4). A disponibilidade de áreas de armazenamento relativamente pequenas diminui a capacidade de amortecimento da máxima vazão. Além disso, o efeito de variações na rugosidade de fundo adotada para as seções laterais tende a ser minimizado.

Um dos resultados da simulação, necessário para a elaboração do PAE, é o mapa de inundação, representando a área atingida pelo nível máximo resultante em cada seção. Como exemplo, a Figura 5 apresenta os mapasde inundação obtidos com as simulações para os cenários (3) e (4).

Os resultados da simulação em regime permanente são úteis para identificar áreas de interesse que podem ser atingidas pela cheia, as quais podem então ser objeto de levantamentos de campo mais detalhados. Essa sequência permitiria racionalizar o trabalho de campo e diminuir o impacto dos dispendiosos levantamentos de campo sobre o custo total. Apesar dessa vantagem, apenas a simulação em regime variável pode estimar o tempo de chegada da inundação.

Como exemplo da informação obtida pela simulação em regime variável apresenta-se a Figura 6, detalhando as ondas de cheia e o tempo, após o início da ruptura, que o nível da água leva para atingir a cota de inundação na Vila Timboré.

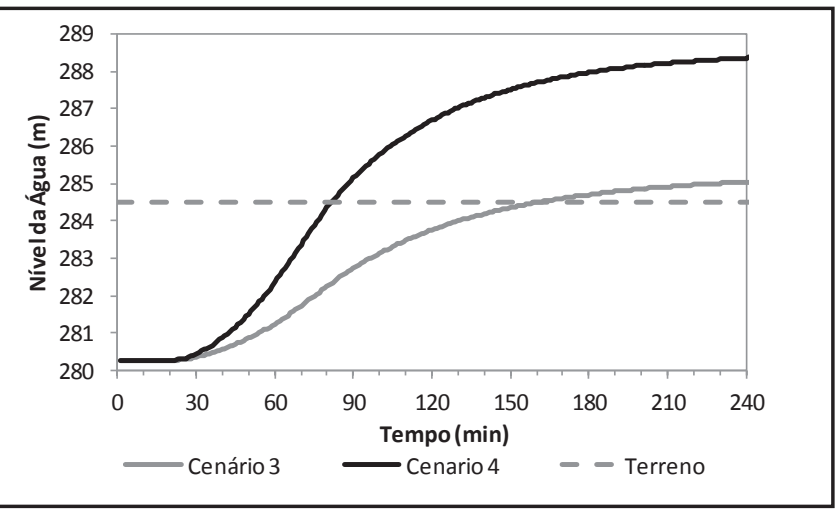

Figura 6- Nível da água em função do tempo na Vila Timboré, para os cenários 3 e 4 , com ruptura em $1 \mathrm{~h}$

Para o cenário de ruptura em 1 hora, o tempo em que o nível da água atinge a cota do terreno na Vila Timboré é de 161 minutos, no caso do cenário (3), e de apenas 82 minutos no caso da maior vazão simulada no cenário (4). Com tempo de abertura da brecha de $14 \mathrm{~h}$, os tempos de chegada da inundação à Vila Timboré foram de $12 \mathrm{~h}$ e $8 \mathrm{~h}$ para os cenários (3) e (4), respectivamente.Esses números dão ideia da ordem de grandeza das variações provocadas pela incerteza na adoção dos parâmetros da brecha. A divulgação de valores ao público num PAE deve considerar este problema, pois dados obtidos com valores superestimados de vazão podem disseminar uma sensação artificial de insegurança, enquanto que valores subes- timados podem tornar inúteis os planos de evacuação.

O período de tempo em que o local ficará submerso também é uma informação útil para o planejamento. A Figura 7 mostra esta informação para a Vila Timboré, com resultados obtidos com tempo de abertura de brecha de $14 \mathrm{~h}$.

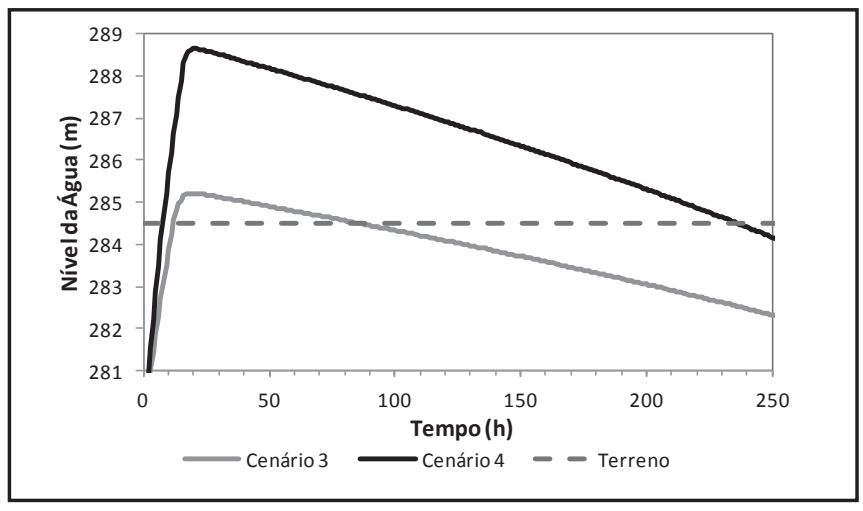

Figura 7 - Nível da água em função do tempo na Vila Timboré, para os cenários 3 e 4 , com ruptura em $14 \mathrm{~h}$

Para o cenário (3), a Figura 7 indica que o terreno ficou submerso entre $12 \mathrm{~h}$ e $86 \mathrm{~h}$ após o início da ruptura. Para o cenário (4), a área permaneceu inundada por praticamente 10 dias (entre 8 h e $236 \mathrm{~h}$ ).

Além do tempo necessário para que o nível da água atinja a cota do local de interesse (tempo de chegada da inundação) e do período de submersão, é necessário registrar a máxima lâmina da água e sua velocidade para calcular o risco hidrodinâmico (R.H.) nos pontos de interesse identificados a partir do mapa estático de inundação. A Tabela 6 resume estas características, importantes para a elaboração do PAE,apartir dos cenários (3) e (4), simulados com $1 \mathrm{~h}$ de tempo de ruptura, para as 4 seções de interesse consideradas: Ponte de Três Irmãos, Vila Timboré, Ponte de Itapura e cidade de Itapura. São apresentados, na Tabela 6 , a profundidade de submersão $(\mathrm{H})$, o tempo de chegada da inundaçãona cota do local de interesse $(\mathrm{T})$, a velocidade da água (V) e o risco hidrodinâmico (R.H.).

As informações sobre os níveis da água, tempo de chegada e risco hidrodinâmico devem ser consideradas em conjunto para produzir os mapas integrantes do PAE. A Figura 8 apresenta o exemplo da cidade de Itapura.

Tabela 6 - Características das ondas de cheia geradas para vazões de $20.915 \mathrm{~m} 3 / \mathrm{s} \mathrm{e} 40.500 \mathrm{~m}^{3} / \mathrm{s}$

\begin{tabular}{|c|c|c|c|c|c|c|}
\hline Local & $\begin{array}{c}\text { Cota } \\
\text { (m) }\end{array}$ & $\begin{array}{c}\text { Cená- } \\
\text { rio. }\end{array}$ & $\underset{(\mathrm{min})}{\mathrm{T}}$ & H (m) & $\begin{array}{c}\mathrm{V} \\
(\mathrm{m} / \mathrm{s})\end{array}$ & $\begin{array}{l}\text { R.H. } \\
\left(\mathrm{m}^{2} / \mathrm{s}\right)\end{array}$ \\
\hline $\begin{array}{l}\text { Ponte } \\
\text { Três } \\
\text { Irmãos }\end{array}$ & 289,47 & $\begin{array}{l}3 \\
4\end{array}$ & $\begin{array}{l}--- \\
107\end{array}$ & $\begin{array}{l}\cdots \\
2,02\end{array}$ & $\begin{array}{l}3,14 \\
4,33\end{array}$ & $\begin{array}{l}\cdots \\
8,74\end{array}$ \\
\hline $\begin{array}{l}\text { Vila } \\
\text { Timboré }\end{array}$ & 284,50 & $\begin{array}{l}3 \\
4\end{array}$ & $\begin{array}{c}161 \\
82\end{array}$ & $\begin{array}{l}0,72 \\
4,12\end{array}$ & $\begin{array}{l}3,21 \\
4,29\end{array}$ & $\begin{array}{c}2,31 \\
17,67\end{array}$ \\
\hline $\begin{array}{l}\text { Ponte } \\
\text { Itapura }\end{array}$ & 283,34 & $\begin{array}{l}3 \\
4\end{array}$ & --- & $\begin{array}{l}--- \\
1,77\end{array}$ & $\begin{array}{l}2,80 \\
3,14\end{array}$ & 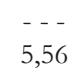 \\
\hline $\begin{array}{l}\text { Cidade } \\
\text { Itapura }\end{array}$ & 281,00 & $\begin{array}{l}3 \\
4\end{array}$ & --- & $\begin{array}{l}--- \\
0,33\end{array}$ & $\begin{array}{l}1,65 \\
2,92\end{array}$ & $\begin{array}{l}\cdots \\
0,96\end{array}$ \\
\hline
\end{tabular}




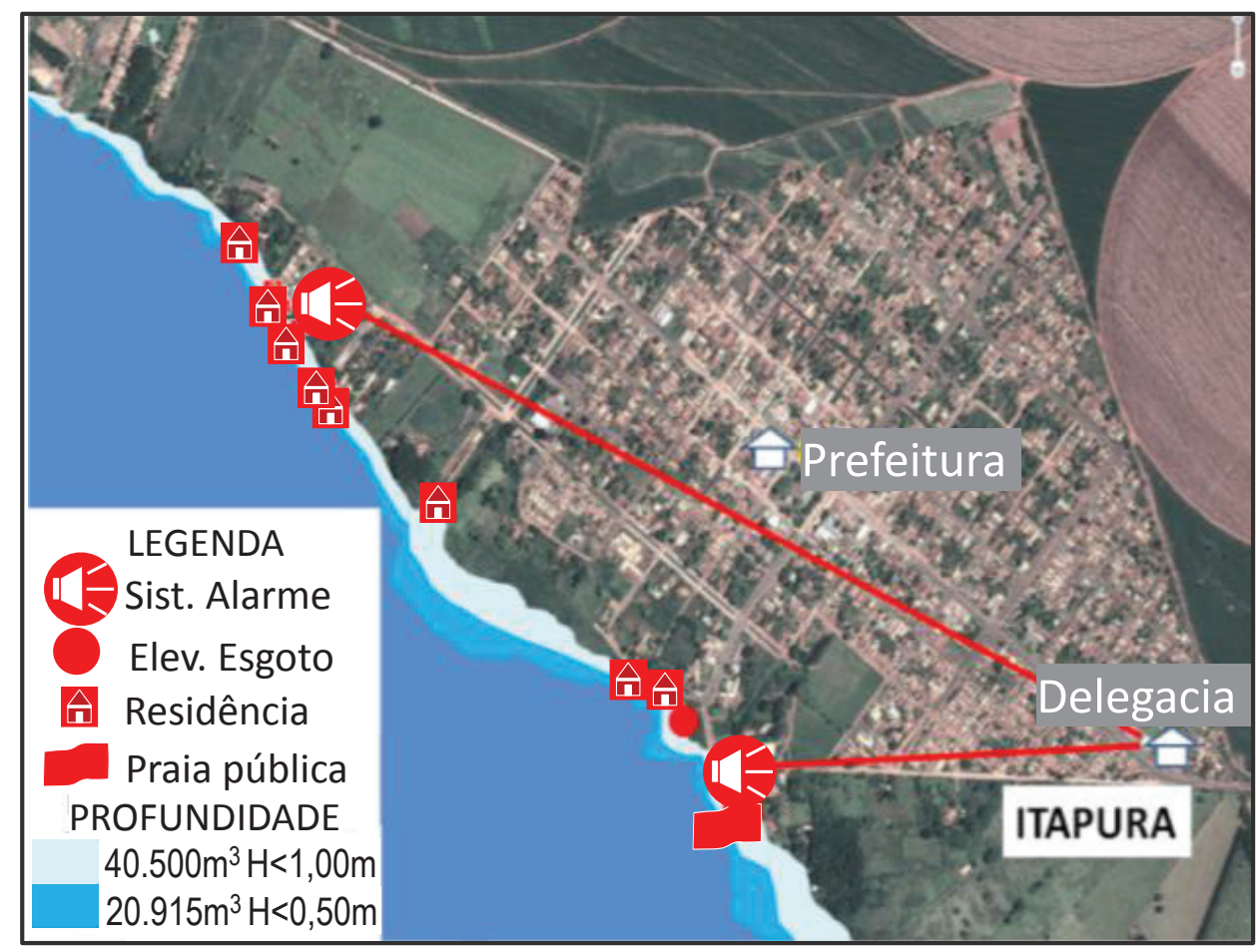

Figura 8 - Modelo do Plano de Ação Emergencial - PAE com locais afetados pela inundação Fonte: Cestari (2013)

\section{CONCLUSÃO}

Os resultados indicam que a proposta metodológica pode ser utilizada para obter mapas de inundação, para elaboração de PAE, devido ao baixo custo dos estudos (US\$10.000) com modelo unidimensional de propagação de cheias.

Adicionalmente, demonstrou-se que a simulação em regime permanente levou a resultados muito semelhantes de nível máximo da água no caso estudado. É razoável defender que esta conclusão possa ser estendida a casos semelhantes, em que a cheia resultante de ruptura de grandes reservatórios é propagada sobre trechos de rio já afetados por barragens, casos esses em que a atenuação por armazenamento nas áreas de inundação é de importância relativamente menor.

Esse contexto vem ao encontro das expectativas da ABRAGE (Associação Brasileira de Empresas de Geração de Energia Elétrica), que estuda a adoção desta metodologia para seus agentes.Os órgãos fiscalizadores também validaram esta metodologia.

Ressalta-se que a barragem de Três Irmãos é bastante segura e possui rotina adequada de monitoramento, contando com instrumentos de auscultação, execução de inspeções rotineiras e periódicas, documentação técnica com registro dessas inspeções e programa anualizado de manutenção.

A barragem Eng. Souza Dias (Jupiá), situada a jusante da Barragem Três Irmãos, no rio Paraná, possui um plano anual de inspeção e manutenção nos órgãos de descarga com capacidade de controlar vazões até cerca de $50.000 \mathrm{~m}^{3} / \mathrm{s} \mathrm{com}$ manobras dos órgãos extravasores.

Como medida de mitigação do risco após o estudo de simulação de ondas de cheia e com base nos resultados obtidos à luz da metodologia, conforme contemplado no PAE - Plano de Ação Emergencial externo, são recomendadas as seguintes medidas de segurança para a população situada a jusante da barragem Três Irmãos, bem como para as estruturas existentes nesta região:

Instalação de um sistema de avisos sonoros para a população da Vila Timboré e da cidade de Itapura;

Instalação de um sistema de sinalização de segurança tipo semáforo nas duas estremidades das pontes de Três Irmãos e Itapura;

O PAE foi entregue para a Defesa Civil dos municipios afetados. Este Órgão deverá fazer o treinamento da população impactada.

Os resultados deste trabalho serão adicionados ao SOSEm (Sistema de Operação em Situação de Emergência), cujas informações irão contribuir com o protocolo de notificação às situações de risco.

\section{AGRADECIMENTO}

Os autores agradecem à CESP por ceder os dados referentes à pesquisa.

\section{REFERÊNCIAS}

ANA - AGÊNCIA NACIONAL DE ÁGUAS. Barragens Cadastradas por Órgãos Fiscalizadores de Barragens no Brasil, 2012. 
Arquivo digital Todas barragens.xlsx. Disponível em <http:// arquivos.ana.gov.br /cadastros/ barragens/ Todas_barragens. xlsx>. Acesso em mar. 2015.

BALBI, D.A.F. Metodologias para a elaboração de Planos de Ações Emergenciais para inundações induzidas por Barragens. Estudo de Caso: Barragem de Peti-MG. 2008. (Mestrado em Engenharia Civil) - Universidade Federal de Minas Gerais, Belo Horizonte, Minas Gerais, 2008.

BRASIL. Lei $n^{\circ}$ 12.334, de 20 de setembro de 2010. Estabelece a Política Nacional de Segurança de Barragens e cria o Sistema Nacional de Informações sobre Segurança de Barragens. República Federativa do Brasil. 2010. Disponível em: < http://presrepublica.jusbrasil.com.br/ legislacao/1025242/lei-12334-10\#art0>. Acesso em mar 2015.

BRASIL. Lei n 12.783, de 11 de jan. de 2013. Dispõe sobre as concessões de geração, transmissão e distribuição de energia elétrica. República Federativa do Brasil. 2013. Disponível em<http:/ /www.planalto. gov.br/ccivil_03/ato2011-2014/2013/lei/L12783.htm>. Acesso em mar. 2015.

BUREAU OF RECLAMATION. Design of small dams. Colorado. Estados Unidos: US Department of the Interior, 1987. 904 p.

CESTARI Jr., E. Estudo de propagação de ondasem planície de inundação para elaboração de plano de ação emergencial de barragens - UHE Três Irmãos Estudo de Caso. 2013. Dissertação. (Mestrado) - Faculdade de Engenharia de Ilha Solteira, Universidade Estadual Paulista, Ilha Solteira, 2013.

CHOW, V.T. Open-Channel bydraulics. Singapore: McGraw-Hill, 1959.

FOSTER, M.; Fell, R.; SPANNAGLE, M. "Risk Assessment Estimating the Probability of Failure of Embankment Dams by Piping", Australian National Committee on Large Dams - ANCOLD, Bulletin, n. 112, p. 41-51, 1999.

HAGEN, V. K. Re-evaluation of design floods and dam safety. In: CONGRESSO DE GRANDES BARRAGENS, 14., 1982, Rio de Janeiro. Anais...Rio de Janeiro, 1982. p. 475-491.

HOGGAN, D.H. Computer-assisted floodplain bydrology and hydraulics. 2nd ed. New York: McGrawHill, 1996.

HYDROLOGIC ENGINEERING CENTER - HEC. HECRAS riveranalysis system: hydraulicreference manual. Davis, California: HEC, 1997.

INTERNATIONAL COMMISSION ON LARGE DAMS ICOLD. Dam break flood analysis: review and recommendations. Paris: ICOLD, 1998. 301 p. (Boletim, 111)

PALMIER, L.R.; BRASIL, L. S. S.; MONTE-MOR, R.C. Modelagem unidimensional de onda de cheia proveniente de ruptura bipotética de barragem-estudo de caso: barragem de Rio de Pedras, Minas
Gerais, Brasil. In: SIMPÓSIO BRASILEIRO DE RECURSOS HÍDRICOS, 16, João Pessoa - PB, 20 a 24 de Novembro de 2005.

VISEU, T.; ALMEIDA; A. B.; MARTINS, R. Plano de emergência Interno de barragens. In: CONGRESSO DA ÁGUA, 5., 2000, Lisboa. Anais... Lisboa, 2000. Disponível em: www.dha.lnec.pt/ nre/portugues/funcionarios papers/tviseu/5cong_agua.pdf. Acesso em: 20 set. 2005.

Von THUN, J.L.; GILLETTE, D.R. "Guidance on breach parameters". Internal Document, U.S. Bureau of Reclamation, Denver, Colorado, 1990. 